American Journal of Animal and Veterinary Sciences 1 (1): 8-12, 2006

ISSN $1557-4555$

(c) 2006 Science Publications

\title{
Inefficacy of Topical Diclofenac in Arthritic Horses
}

\author{
Nicolás F. Villarino, Tomas J. Vispo, Marcos, Ferrante and María F. Landoni \\ Pharmacology Department. Faculty of Veterinary Science. University of La Plata \\ Calle 60 y 118 cc 296 (B1900AVW) La Plata. Argentina
}

\begin{abstract}
The objective of the present study was test the anti-inflammatory efficacy of diclofenac dietilamine, applied epicutaneously at a dose rate of $0.44 \mathrm{mg} \mathrm{kg}^{-1}$, in a model of acute arthritis in horses. Four clinical end-points, as well as two biochemical markers, were used as surrogate markers of the required clinical response (analgesia, anti-inflammatory). Low diclofenac concentrations were measured in blood $\left(\mathrm{C}_{\max } 0.04 \pm 0.03 \mathrm{ug} \mathrm{mL}^{-1}\right)$ and synovial fluid $\left(\mathrm{C}_{\max } 0.08 \pm 0.08 \mathrm{ug} \mathrm{mL}^{-1}\right)$ from the first to the last sampling time. The statistical comparison of the clinical end-points and biochemical markers between placebo and dicilofenac treated group indicated a lack of pharmacological effect of this compound after epicutaneous administration.
\end{abstract}

Key words: NSAIDs, horse, arthritis, diclofenac, transdermal

\section{INTRODUCTION}

Arthritis is the commonest joint disease in sport horses. Its therapy is directed towards the provision of analgesia, limitation of inflammation and limitation of the damage to joint tissues.

Non-steroidal anti-inflammatory drugs (NSAIDs) are routinely used in horses for the treatment of pain and inflammation ${ }^{[1]}$. These drugs are usually administered orally or by injection. Although, systemic administration has many disadvantages such as, toxic effects (gastrointestinal and renal toxicity) mainly attributed to COX-1 inhibition.

The treatment of a joint condition through topical drug administration led to better drug targeting, mainly, the synovial fluid ${ }^{[2,3]}$. Topical administration of NSAIDs provides the advantage of achieving a therapeutic effect without the risk of potential severe systemic side effects that may be associated with systemic administration.

Diclofenac, a phenylacetic acid class NSAID, is an effective analgesic ${ }^{[4]}$, with potent COX inhibitory activity that is administered extensively for the treatment of various arthritic conditions in $\operatorname{man}^{[5]}$. However, there are not many reports about the antiinflammatory effects of diclofenac in horses. In addition, the anti-inflammatory effects of diclofenac applied topically have not been studied in horses suffering acute arthritis.

The effectiveness of a topical formulation depends on the ability of the formulation to dispense effective concentrations of drug at the biophase. The two major pathways of drug transport into and across skin are: (a) the transepidermal route across the stratum corneum and (b) the transfollicular route via the pilosebaceous units and shunts.
Drug penetration could be affected by many factors including, skin thickness, chemical structure of the active principle, anatomical region and qualitative characteristic of the formulation ${ }^{[6-8]}$. These factors could modify the penetration of drugs through the skin determining the achievement of effective concentrations at the site of action, this situation being reflected in the clinical efficacy.

In the present study, in order to evaluate the anti inflammatory effects of diclofenac administered epicutaneuosly, an experimental model of acute arthritis was used $^{[1,9,10,11]}$.

\section{MATERIALS AND METHODS}

Experimental animals: Animals were six standard breed mares weighting $400 \pm 20 \mathrm{~kg}$. Inclusion criteria were over 2 year old, non-gestating mares, no previous joint inflammatory process and non-current or previous systemic immune disease. The animals were housed indoors in individual box stalls and fed a maintenance ration of hay twice daily. Water was freely available.

The total surface of each carpal joint was established considering it as a cylinder $(\varnothing \mathrm{x} \mathrm{h})$. The calculated total surface of treatment was $450 \mathrm{~cm}^{2}$. (Circumference $[\varnothing]: 30 \mathrm{~cm}$ and height $[\mathrm{h}]: 15 \mathrm{~cm}$ ). All animal procedures were approved by the Secretaría de Ciencia y Técnica, Universidad Nacional de La Plata, Argentina.

Experimental design and sampling procedures: Diclofenac diethylamine (Átomo Desinflamante®. IMVI. S.A Argentina) $1.16 \%$ (equivalent to $1 \mathrm{~g}$ sodium diclofenac) was purchased to a local dealer. A twoperiod cross over Latin square design was used, such

Corresponding Author: $\quad$ María F. Landoni, Cátedra de Farmacología. Facultad de Ciencias Veterinarias. Universidad Nacional de La Plata. Calle 60 y 118 cc 296 (B1900AVW) La Plata. Argentina 
that each horse received diclofenac diethylamine (DFD) and placebo (PL) treatment.

During the first period 3 animals (Group A) received a dose of $0.44 \mathrm{mg} \mathrm{cm}^{-2}$ DFD. The group B received an equivalent amount of placebo (Átomo Desinflamante ${ }^{\circledR}$ without active principle). An interval of 3 weeks was allowed between each period.

Induction of synovitis and sampling schedule: Acute synovitis was induced in the carpal joint (left in period I and right on II). A $1 \mathrm{~mL}$ aliquot of saline containing 1 $\mu \mathrm{g}$ LPS $\left(0.01 \mu \mathrm{g} \mathrm{kg}^{-1}\right)$ (Escherichia coli O55 B5, Sigma Chemical Co, St Louis USA) was injected into the joint at the same time as drug administration (Time 0).

\section{Dosing schedule}

Group A: $0.44 \mathrm{mg} \mathrm{cm}^{-2}$ DFD (total dose $20 \mathrm{~g}$ of Átomo Desinflamante $\left.{ }^{\circledR}\right)$, was rubbed into the skin every $8 \mathrm{~h}$ during 4 days. To assure complete distribution of the formulation a 2 minutes mild massage was applied after each administration. To avoid carry over effect of the previous administration, a complete cleaning of the administration site with clorhexidine and hot water was made previous to drug administration.

Group B: $20 \mathrm{~g}$ of PL (Átomo Desinflamante ${ }^{\circledR}$ without diclofenac) was rubbed into the skin by two minutes of mild massage every $8 \mathrm{~h}$ during 4 days.

Blood and synovial sampling: Blood samples $(5 \mathrm{~mL})$ were withdrawn from the jugular vein at $0,1,3,6,9,12$, 24, 36, 48, 72 and 96h, into lithium heparin tubes. After centrifugation $(2200 \mathrm{~g}, 10 \mathrm{~min})$, plasma was separated and stored at $-20^{\circ} \mathrm{C}$ until DFD plasma concentration analysis was performed.

Synovial fluid $(3 \mathrm{~mL})$ from inflamed joints was collected by syringe and needle at $0,1,3,6,9,12,24$, $36,48,72,96 \mathrm{~h}$ into lithium heparin tubes. Samples were centrifuged $(2200 \mathrm{~g}, 10 \mathrm{~min})$ and stored at $-20^{\circ} \mathrm{C}$ until assay.

Measurements and analytical methods: Four pharmacodynamic end points were measured according a standardized procedure before and 1, 3, 6, 9, 12, 24, $36,48,72$ and $96 \mathrm{~h}$ after test product administration. All measurements were taken by the same trained investigators.

The stride length (an indicator of lameness) was measured by walking the horse on a hard surface and measuring the distance between hoofprints of the affected limb. A total of ten consecutive strides were measured. After eliminating the two extreme values, the mean stride length was calculated.

The circumference of the inflamed joint (carpal swelling) was measured with a flexible rule at the top of the carpus using the same anatomical reference points.
A single measurement was carried out at each sampling time.

Rest angle flexion and maximal carpal flexion (an indicator of pain) were measured with a home made goniometer. One measurement was carried out at each sampling time. First, the rest angle flexion was measured; the lame leg was progressively flexed until occurrence of a pain reaction. This manoeuvre permitted calculation of two parameters expressed in degrees: the rest angle and maximal carpal flexion.

Total protein concentration in synovial fluid was measured by Lowry' method as described by Schacterle and Pollack ${ }^{[12]}$.

Total glycosaminoglycan concentration was evaluated by Farndale' method, modified by Alwan $^{[13,14]}$.

Concentrations of diclofenac in synovial fluid and plasma samples were measured by an HPLC method with UV detection described by Krishna \& Surja Kumar (1991). Briefly, $1 \mathrm{~mL}$ of McIlvane's buffer and 5 $\mathrm{mL}$ of ethyl ether were added to a $1 \mathrm{~mL}$ sample. The mix was centrifuged (5000 x g for 10 minutes). The organic layer $(4 \mathrm{~mL})$ was transferred into a clean tube and evaporated at $45{ }^{\circ} \mathrm{C}$ under nitrogen stream. The residue was reconstituted with $200 \mu \mathrm{L}$ methanol containing $1 \mu \mathrm{g} \mathrm{mL}^{-1}$ IS (tolfenamic acid). A $20 \mu \mathrm{L}$ aliquot of the sample was injected onto an HPLC system comprising a Digital pump series II (Konik Instruments, Argentina), an absorbance detector, (Konik 200) and a SP4600 integrator. The chromatograph consisted of a spherisorb RPC18 $7 \mu \mathrm{m}(250 \times 4.6 \mathrm{~mm})$ column and a spherisorb $\mathrm{RPC}_{18} 5 \mu \mathrm{m}$ precolumn; the mobile phase was acetonitrile:HPLC water: acetic acid (59:49:2) and the flow rate $1 \mathrm{~mL} \mathrm{~min}^{-1}$. The detection wavelength was 280 $\mathrm{nm}$ and the detection limit of the method was $0.05 \mu \mathrm{g}$ $\mathrm{mL}^{-1}$. The coefficient of variation over the calibration range of 10 to $0.01 \mu \mathrm{g} \mathrm{mL}^{-1}$ was less than $10 \%$.

Statistical analysis: Statistical analysis was conducting using the Software Prisma Graph Pad package (Graph Pad Software, Inc. San Diego, California and U.S.A.).

Descriptive statistical calculations included mean and standard deviation (SD). Pharmacodynamic effects were standardized before inferative analysis, according to individual baseline values as percentage of change (100\% corresponding to baseline value). Since the objective of the study was to analyze clinical effects of DFD over a relatively long period of time, a scheme for repeated samples (based on the area under the curve percentage change from baseline vs. time) was applied $^{[15]}$.

The areas under the curve percentage change from baseline vs. time were calculated with the following equation

AUC $=0.5 \sum_{I=0}^{n-1}\left(\mathrm{t}^{\mathrm{i}+1}-\mathrm{t}^{\mathrm{i}}\right)\left(\mathrm{y}^{\mathrm{i}}+\mathrm{y}^{\mathrm{i}+1}\right)$ 
Where " $\mathrm{t}$ " is sampling time and " $\mathrm{y}$ " the observed measurement.

\section{RESULTS AND DISCUSSION}

Diclofenac was detected in blood and synovial fluid from the first to the last sampling time. Peak plasma $\left(0.04 \pm 0.03 \mu \mathrm{g} \mathrm{mL}^{-1}\right)$ and synovial $(0.08 \pm 0.08$ $\mu \mathrm{g} \mathrm{mL}^{-1}$ ) concentration were recorded between 3 and 9 $\mathrm{h}$ and at $1 \mathrm{~h}$ post-LPS, respectively.

Pharmacodynamic effects: Figure 1 plots the evolution in relation to time (h) of the mean response (expressed as percentage of variation) for DFD and PL for the four assessed clinical end-points.

Table 1 gives the maximum response observed for DFD and PL its time of occurrence and the calculated AUC for the four assessed clinical end-points.

Maximal response is expressed as a percentage of control values. Maximal response corresponds to the highest value obtained after averaging data of the six horses at each sampling time. AUC corresponds to the values of each treatment group for all clinical end-points during the whole study (0-96h)

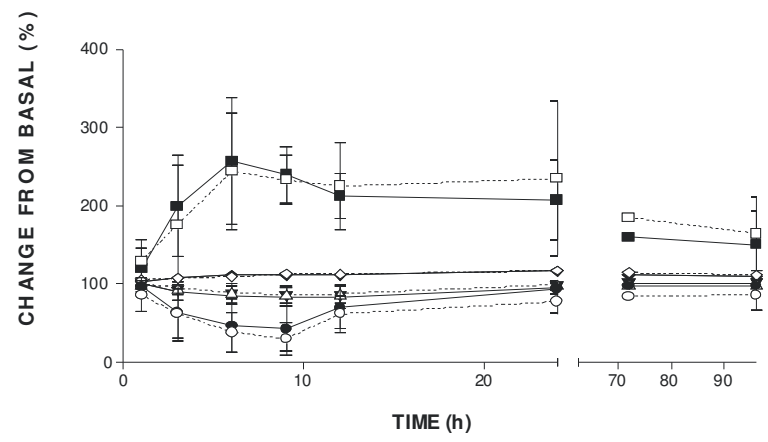

Fig. 1: Plot against time of mean \pm SD percentage of change from basal stride lenght $(\bullet)$, carpus circumference $(\bullet)$, rest angle flexion $(\boldsymbol{\Delta})$ and maximal carpal flexion (ם) after the epicutaneously application of diclofenac ( $0.44 \mathrm{mg} \mathrm{cm}^{-2} / 8 \mathrm{~h}$ ) or placebo (empty symbols) during $96 \mathrm{~h}$.

Stride length: All the experimental animals decreased their stride length after the LPS intraarticular administration. The maximum decrease was observed in the PL treated group $9 \mathrm{~h}$ post injection, being the maximum mean value $70 \%$. Even though the stride length improved, the last measured value was $0.86 \pm$ 0.19 indicating that the experimental animals did not reach their basal value. The mean AUC for the animals treated with PL was 40.94 8.79.
Table 1: Effects of Diclofenac diethylamine (DFD) (0.44 mg $\mathrm{cm}^{-2} / 8 \mathrm{~h}$ ) and Placebo (PL) (20g), applied epicutaneously, on different clinical end-points in six horses with experimental carpus arthritis

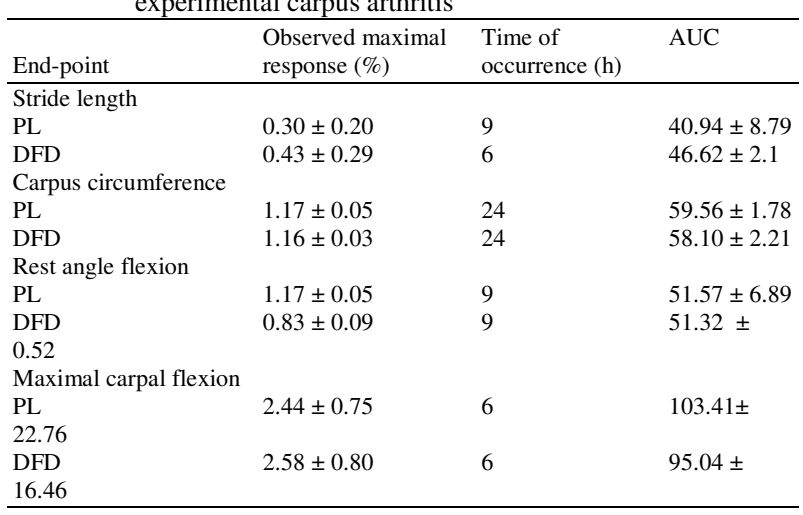

As regards to the DCF group, it was observed a similar temporal profile to the control group. The maximum decrease was observed $6 \mathrm{~h}$ post LPS with a maximum mean value of $57 \%$. The area under the curve percentage of change as function of time showed numerical differences between the two experimentally groups. However, these differences did not reach statistical significance. $(\mathrm{p}>0.05)$

Circumference of the inflamed joint: In all two experimental groups, carpal circumference showed an increase within the first hour post-injection of LPS. In the PL treated group, the maximum percentage of change from the baseline (17\%) was recorded at $24 \mathrm{~h}$ post LPS. Calculated mean AUC was $59.56 \pm 1.78$.

The group of DFD treated animals showed a similar temporal profile to the PL group, although recorded maximum change from the baseline was smaller (14\%). The mean AUC was 58.10 2.21.

In spite of the numerical differences between the two experimentally groups, the complete analysis of the process $(0-96 \mathrm{~h})$ through the AUC, did not showed statistically significant differences $(p>0.05)$.

Rest angle: Differences of this parameter between the two experimentally groups were minimal. In all experimental groups a decrease in the rest angle was observed during the third hour post-LPS, returning in all cases to the baseline values.

Maximal carpal flexion: In the PL treated group the increase of this parameter was evident from the first hour post LPS. The mean maximum change (144\%) was observed $6 \mathrm{~h}$ post LPS. At the last sampling time none of the animals had recovered their baseline value. The mean AUC was 103.41 22.76.

In the DFD treated group the mean maximum change $(158 \%)$ was observed $6 \mathrm{~h}$ post-LPS. The mean AUC was $95.04 \pm 16.46$.

The observed differences between the two treated groups were not statistically significant. 


\section{Synovial biochemical markers: Glycosaminoglycans: The intraarticular injection of LPS induced an increase of the total GAGs concentration in all PL treated animals with a peak $\left(114 \pm 38.31 \mu \mathrm{g} \mathrm{mL}^{-1}\right)$ between 12 and $24 \mathrm{~h}$. The mean AUC was 2953.1 2203 in the DFD treated group, the temporal profile of GAGs concentration in synovial fluid was similar to the PL group being the maximum concentration registered $60.95 \pm 17.15 \mu \mathrm{g} \mathrm{mL}^{-1} 12 \mathrm{~h}$ post LPS. In both groups $96 \mathrm{~h}$ post-LPS injection GAGs synovial concentration showed a clear tendency to return to the baseline. \\ No statistically significant differences where observed between treated groups.}

Proteins: The intraarticular injection of LPS induced an increase of the total protein concentration in both treated groups with a peak of $10.9 \pm 2.6 \mathrm{~g} \mathrm{dL}^{-1}$ at $24 \mathrm{~h}$ and $10.8 \pm 3.0 \mathrm{~g} \mathrm{dL}^{-1}$ at $9 \mathrm{~h}$ post LPS for PL and DFD, respectively.

No statistically significant differences were observed between groups.

In the present study the injection of LPS induced a mild, reversible and reproducible inflammatory response in all horses.

The capacity of diclofenac to reduce the clinical signs associated to acute inflammation after oral and topical administration has been demonstrated in humans ${ }^{[16-18]}$. However, there are not reports on the effectiveness of this drug in spontaneous or induced acute inflammation in horses.

In the present study, four clinical end-points were used as surrogate markers of the required clinical response (analgesia, anti-inflammatory) ${ }^{[9,19]}$.

The statistical analysis of the clinical end-points indicates the lack of differences between the two treated groups. These data reveal that the studied topical formulation of diclofenac dietilamine administered at dose rate of $0.44 \mathrm{mg} \mathrm{cm}^{-2}$ every $8 \mathrm{~h}$ during 4 days is ineffective to reduce the clinical signs associated with acute arthritis. The same holds true for the biochemical markers evaluated in synovial fluid.

Contrary to our results, Bertone et al. ${ }^{[20]}$ have reported the clinical efficacy of diclofenac (at a considerably lower dose), when it was administrated topically through a liposomal formulation. However, it is important to consider that the animals included in this study were suffering chronic arthritis. In addition, in this study evaluation of clinical signs was performed by applying a visual scale, which could suggest some subjectivity in the results ${ }^{[21]}$. In fact, it has been reported that positive results obtained by visual scale can be reversed by application of more objective scales, such as WOMAC ${ }^{[22]}$.

The effects of NSAIDs are principally due to the inhibition of prostaglandins synthesis. However, to achieve a therapeutically useful response (antipyretic, anti-inflammatory, analgesic or antiedematous), a high level of inhibition is required (IC95) ${ }^{[23]}$.

Caldwell et al. ${ }^{[24]}$ has recently reported using a topically administered liposomal formulation of diclofenac over an inflamed tissue cage, that $76.2 \pm 29$ $\mathrm{ng} \mathrm{mL}^{-1}$ was enough to reduce significantly the synthesis of $\mathrm{PGE}_{2}$. This concentration is considerably higher than the synovial fluid concentration recorded in our study (mean $0.60 \pm 0.30 \mathrm{ng} \mathrm{mL}^{-1}$ ).

In this context, considering the clinical efficacy of diclofenac reported, both in humans and horses, by other authors it is important do not misinterpret the present results assuming that diclofenac was ineffective to treat arthritis. The results are clearly showing that the tested formulation was not capable to reach effective concentrations at the biophase.

The largest organ of the body, the skin, is an amazingly resilient and relatively impermeable barrier that provides protective, perceptive and communication functions to the body.

There are at least twenty factors that can affect the penetration of drugs thought the skin including a)characteristics of the skin and b)- physiochemical properties of the drugs formulation such as, molecular mass, adequate solubility in oil and water and a high optimal partition coefficient ${ }^{[25]}$.

The stratum corneum is the limiting step to permeability of drug trough the $\operatorname{skin}^{[26]}$. In fact, there are a number of substances, known as chemical penetration enhancers (CPE), that could be used in order to enhance the penetrability of drugs by altering the stratum corneum structure ${ }^{[27]}$.

It has been demonstrated, that the penetration of diclofenac differs depending on the formulation ${ }^{[25,28]}$. In our laboratory penetration through horse skin of a number of diclofenac formulations for topical administration were evaluated in vitro with disappointing results, since most of them had very low penetration rate (unpublished results).

Another important point to be considered is the relationship between qualitative characteristics of the formulation and the activity of the formulation as a system. Although, the need of a CEP - in order to maximize the drug penetration is undeniable- it is, also, essential that the formulation releases the active ingredient.

\section{CONCLUSION}

Based on the present results, it is possible to conclude that the inefficacy of the Átomo Desinflamante ${ }^{\circledR}$ is related to the low concentration of diclofenac reaching the site of action. Thus, in spite of the many benefits that topical administration offers, it is necessary to consider the characteristics of the commercial product in order to treat properly pathological conditions such as, acute arthritis. 


\section{REFERENCES}

1. Blikslager, A.T., 2005. NSAIDs. J. Equine Veterinary Sci., 25: 98-102.

2. Dehghanyar, P., B.X. Mayer, K. Namiranian, H. Mascher, M. Mueller and M. Brunner, 2004. Topical skin penetration of diclofenac alters single -and multiple dose application. Intl. J. Clin. Pharmacol. Therap., 42: 353-359.

3. Elmquist, W.F., K.K. Chan and R.J. Sawchuk, 1994. Transsynovial drug distribution: synovial mean transit time of diclofenac and other non-steroidal anti-inflammatory drugs. Pharmacol. Res., 11: 1689-1697.

4. Giuliano, F. And T.D. Warner, 2002. Origins of prostaglandin $\mathrm{E}_{2}$ : involvements of cyclooxygenase (COX)1 and COX-2 in human and rat systems. J. Pharmacol. Expl. Thererap., 303: 1001-1006.

5. Moore, R.A., S. Derry, G.T. Makinson and H.J. McQuay, 2005. Tolerability and adverse events in clinical trials of celecoxib in osteoarthritis and rheumatoid arthritis: systematic review and metaanalysis of information from company clinical trial reports. Arthritis Res. Ther., 3: 644-65.

6. Higaki, K., K. Nakayama, T. Suyama, C. Amnuaikit, K. Ogawara and T. Kimura, 2005. Enhancement of topical delivery of drugs via direct penetration by reducing blood flow rate in skin. Intl. J. Pharmaceutics, 288: 227-233.

7. Roberts, M.S., S.E. Cross and Y.G. Amissimov, 2004. Factors affecting the formation of a skin reservoir for topically applied solutes. Skin Pharmacol. Physiol., 17: 316.

8. Cevc, G. and G. Blume, 2001. New highly efficient formulation of diclofenac for the topical, transdermal administration in ultradeformable drug carriers. Transfersomes. Biochemica et Biophysica Acta Biomembranes, 1014: 191-205.

9. Verde, C.R., M.I. Simpson, A. Frigoli and M.F. Landoni, 2001. Enantiospecific pharmacokinetics of ketoprofen in plasma and synovial fluid of horses with acute synovitis. J. Vet. Pharmacol. Thererap., 24: 179-85.

10. Verde, C.R., N.F. Villarino, M.I. Simpson, A. Frigoli and M.F. Landoni, 2005. Therapeutics and hematological effects of native and low molecular weight condroitin sulfate administered orally in horses with arthritis. REDVET Electronic J., VII:1: 10605.

11. Morton, A.J., N.B. Campbell, J.M. Gayle, R. Redding and A.T. Blikslager, 2005. Preferential and non-selective cyclooxygenase inhibitors reduce inflammation during lipopolysaccharide-induced synovitis. Res. Vet. Sci., 78: 189-192

12. Schacterle, G.R. and L.R. Pollack, 1973. A simplified method for the quantitative assay of small amounts of protein in biologic material. Anal. Biochemical., 51: 654-655.

13. Farndale, R.W., D.J. Buttle and A.J. Barrett, 1986. Improved quantitation and discrimination of sulphated glycosaminoglycans by use of dimethylmethylene blue. Biochim. Biophys. Acta, 883: 173-177.

14. Alwan, W.H, S.D. Carter, D. Bennet and G.B. Edwards, 1991. Glycosaminoglycans in horses with osteoarthritis. Equine Vet. J., 23: 44-7.
15. Matthews, J.N., D.G. Altman, M.J. Campbell and P. Royston, 1990. Analysis of serial measurements in medical research. Br. Med. J., 300: 230-235.

16. Cheng, T., H. Lai, C. Chui and Y. Chen, 2004. A singlebling randomized controled trial to assess the efficacy and tolerability of rofecoxib, diclofenac sodium and meloxicam in patients with acute gouty arthritis. Clin. Therap., 26: 399-406.

17. Galer, S., M. Rowbotham, J. Perander, A. Devers and E. Friedman, 2000. Topical diclofenac patch relieves minor sports injury pain. J. Pain and Symptom Management, 19: 287-294.

18. Bookman, A., K. Williams and J. Shaihouse, 2004. Effect of a topical diclofenac solution for relieving symptoms of primary osteoarthritis of the knee: A randomized controlled trial. Can. Med. Assoc. J., 17: 171-174.

19. White, G.W., T. Stites, W. Jones and S. Jordan, 2004. Efficacy of intramuscular chondroitin sulfate and compounded acetyl-d-glucosamine in a positive controlled study of equine carpitis. Proc. 50th American Association Equine Practitioners Convention, Colorado, USA, pp. 254269

20. Theiler, R, P. Ghosh and P. Brooks, 1994.Clinical, biochemical and imaging methods of assessing osteoarthritis and clinical trials with agents claiming 'chondromodulating' activity. Osteoarthritis Cartilage, 1: $1-23$.

21. Bertone, J.J., R.C. Lynn, N.J. Vatistas, W.J. Kelch, R.G. Sifferman and D.I. Hepler, 2002. Clinical fiel trial to evaluate the efficacy of topically applied diclofenac liposomal cream for the relief of joint lameness in horses. Proc. 48th Am. Assoc. Equine Practitioners Convention, Floriada, USA, pp: 190-193.

22. Cohen, M., R. Wolfe, T. Mai and D. Lewis, 2003. A randomized, double blind, placebo controlled trial of a topical cream containing glucosamine sulfate, chondroitin sulfate and camphor for osteoarthritis of the knee. J. Rheumatol., 30: 523-528.

23. Lees, P., 2003. Pharmacology of drugs used to treat osteoarthritis in veterinary practice. Inflammopharmacology, 11: 385-399.

24. Caldwell, F.J., C.E. Mueller, R.C. Lynn and S.C. Budsberg, 2004. Effect of topical application of diclofenac liposomal suspension on experimentally induced subcutaneous inflammation in horses. Am. J. Vet. Res., 65: 271-276.

25. Barry, B.W., 2004. Breaching the skin's barrier to drugs. Nature Biotechnol., 22: 165-167.

26. Ramachandran, C. and D. Fleisher, 2000. Transdermal delivery of drugs for the treatment of bone diseases. Advance Drug Delivery Review, 42: 197-223.

27. Karande, P., A. Jain and S. Mitagotri, 2004. Discovery of transdermal penetrationenhancers by high-throughput screening. Nature Biotechnol., 22: 192-197.

28. Escribano, E., A.C. Calpena, J. Queralt, R. Obachand and J. Doménech, 2003. Assessment of diclofenac permeation with different formulations: anti-inflammatory study of a selected formula. Eur. J. Pharmaceutical Sci., 19: 203-210. 